\title{
MicroRNA-24 inhibits CDX1 expression in decidual tissues of recurrent spontaneous abortion mice to reduce the abortion risk
}

\author{
Shuyan Wang ${ }^{1, A-D}$, Shishan Guo ${ }^{2,, E}$, , Xiaoyan Hou ${ }^{1, A, B, D-F}$ \\ ${ }^{1}$ Department of Clinical Laboratory, Maternity and Child Health Care Hospital of Zaozhuang, China \\ 2 Department of Blood Transfusion, Maternity and Child Health Care Hospital of Zaozhuang, China \\ A - research concept and design; B - collection and/or assembly of data; C - data analysis and interpretation; \\ $D$ - writing the article; $E$ - critical revision of the article; $F$ - final approval of the article
}

\section{Address for correspondence \\ Xiaoyan Hou}

E-mail:houxiaoyan4d7k@163.com

Funding sources

None declared

Conflict of interest

None declared

Received on January 13, 2020

Reviewed on February 5, 2020

Accepted on May 8, 2020

Published online on August 21, 2020

\begin{abstract}
Background. Recurrent spontaneous abortion (RSA), presenting as one of the difficult clinical diseases, has a high incidence rate among women of reproductive age, with a rising trend in recent years.

Objectives. To confirm a target relationship between miR-24 and CDX1. This study aimed to explore miR-24 expression in decidual tissue under recurrent spontaneous abortion (RSA) and its mechanism of regulating downstream gene CDX1.
\end{abstract}

Material and methods. Female CBA/J mice were mated with male BALB/C mice to establish normal pregnancy models, and mated with male DBA/2 mice to establish RSA models. Recurrent spontaneous abortion model mice were randomized into 5 groups: a model group, a NC group, a miR-24 mimic group, a CDX1 vector group, and a miR-24 mimic+CDX1 vector group. Expressions of miR-24, CDX1, VEGF, cleaved caspase-3, Fas, and FasL, as well as apoptosis in decidual tissues, embryonic development and embryo loss rate were compared.

Results. Compared with the normal group, the embryo loss rate, apoptosis rate, and the expressions of cleaved caspase-3, Fas and CDX1 in decidual tissue in other groups were significantly increased, and the expressions of miR-24, VEGF, and FasL were significantly decreased (all $p<0.05$ ). The miR-24 mimic group showed the opposite changes when compared with the model group (all $p<0.05$ ). However, CDX1 overexpression can significantly block the protective effect of miR-24 overexpression on embryonic development $(p<0.05)$.

Conclusions. MiR-24 can inhibit CDX1 expression in decidual tissue of RSA mice, thus improving the embryonic development of the mice and reducing the RSA risk.

Key words: spontaneous abortion, caudal-type homeobox protein 1, microRNA-24

Cite as

Wang S, Guo S, Hou X. MicroRNA-24 inhibits CDX1 expression in decidual tissues of recurrent spontaneous abortion mice to reduce the abortion risk. Adv Clin Exp Med. 2020;29(8):929-936. doi: 10.17219/acem/122173

DOI

10.17219/acem/122173

Copyright

Copyright by Author(s)

This is an article distributed under the terms of the

Creative Commons Attribution 3.0 Unported (CC BY 3.0)

(https://creativecommons.org/licenses/by/3.0/) 


\section{Introduction}

Recurrent spontaneous abortion (RSA) is defined as 3 consecutive pregnancy losses in a woman of reproductive age in the setting of 1 identical sexual partner. ${ }^{1,2}$ Recurrent spontaneous abortion, presenting as a difficult clinical disease, has a high incidence rate among women of reproductive age, with a rising trend in recent years. ${ }^{3,4}$ Exploration on the mechanism of RSA can enrich the theoretical basis in clinical treatment and thus may provide new critical ideas for RSA treatment.

We found that caudal-type homeobox 1 (CDX1) was significantly overexpressed in RSA through preliminary experiments. No research at present has confirmed the mechanism of CDX1 affecting RSA. One research study showed that the expression of enhancer of zeste homologue 2 (EZH2) was significantly downregulated in RSA, and 1 other research study through chromatin immunoprecipitation assay confirmed that EZH2 was obviously bound with CDX1, and through dual-luciferase reporter gene assay verified that EZH2 could negatively regulate CDX1 expression.,6 Therefore, we speculated that CDX1 may be a crucial target in RSA. However, the deeper significance and potential mechanism of CDX1 in RSA are still unclear. To date, many studies have reported microRNA expression regulation in RSA. ${ }^{7-11}$ Some studies have shown that miR-24 expression is downregulated in decidual NK cells. ${ }^{12-14} \mathrm{MiR}-24$ regulates posttranscriptional expressions mainly by targeting downstream genes. Collectively, miR-24 may also serve as an important regulatory factor affecting RSA. As a result, we screened the downstream target genes of miR-24 and found that there was a binding site between CDX1 and miR-24. Therefore, we further speculated that miR-24 may highly possibly serve as the upstream regulatory component of CDX1 in RSA.

In this study, we constructed RSA mouse models and conducted overexpression on miR-24 and CDX1 in order to explore the expression regulation relationship between miR-24 and CDX1 in the decidual tissues of RSA model as well as its effect on RSA.

\section{Methods}

\section{Animals}

One hundred and twenty specific pathogen-free female $\mathrm{CBA} / \mathrm{J}$ mice, 10 male BALB/C mice and 50 male DBA/2 mice at 6-8 weeks of age were selected in this study. The mice were raised in animal rooms at suitable temperature, under a 12/12-hour dark/light cycle with ad libitum access to standard rodent diet and water throughout the study. All procedures were approved by the Animal Care and Use Committee and conformed to the revised (1996) Guide for the Care and Use of Laboratory Animals published by the US National Institutes of Health (NIH). This study was reviewed and approved by the local ethics committee.

\section{Animal modeling and grouping}

The normal pregnancy models were constructed by mating $\mathrm{CBA} / \mathrm{J}$ female mice with BALB/C male ones, while RSA models were made by mating CBA/J female mice with DBA/2 male ones. Twenty CBA/J female mice and $10 \mathrm{BALB} / \mathrm{C}$ male ones were mated in a ratio of 2:1, while $100 \mathrm{CBA} / \mathrm{J}$ female mice and $50 \mathrm{DBA} / 2$ male ones were mated in the same ratio. ${ }^{15,16}$ The presence of a vaginal plug marked that day as embryonic day 0 in a pregnant mouse, and finally 20 normal pregnancy model mice and 100 RSA model mice were obtained.

The RSA model mice were randomized into 5 groups on average, the model group (RSA mice without other treatment), the NC group (RSA mice with injection of miR$24 \mathrm{NC}$ and transfection reagent through caudal vein), miR24 mimic group (RSA mice with infection of miR-24 mimic and transfection reagent through caudal vein), the CDX1 vector group (RSA mice with injection of pcDNA3.1-CDX1 overexpression vector), and the miR-24 mimic+CDX1 vector group (RSA mice with injection of miR-24 mimic and pcDNA3.1-CDX1 overexpression vector). MiR-24 mimic NC, miR-24 mimic and pcDNA3.1-CDX1 were all purchased from Guangzhou RiboBio Co., Ltd., Guangzhou, China. MiR-24 mimic NC, NC vector, miR-24 mimic, and pcDNA3.1-CDX1 were mixed with $50 \mu \mathrm{L}$ culture medium and with $50 \mu \mathrm{L}$ Entranster ${ }^{\mathrm{TM}}$-in vivo transfection reagent. According to the grouping, the mixed solutions were injected into the corresponding mice through the caudal vein at a dose of $2 \mathrm{mg} / \mathrm{kg}$. The first intravenous injection was carried out at the time of mating in the cage; then, the same injection was performed at three-day intervals until the $14^{\text {th }}$ day after conception. The mice were sacrificed at day 14 after conception, and the uteri of the mice were then removed out for observation on the embryonic development and the calculation on the embryo loss rate.

\section{Quantitative reverse-transcriptase PCR}

Decidual tissues of the mice in each group were taken and ground into homogenate for quantitative reverse-transcriptase polymerase chain reaction (qRT-PCR) analysis. Total RNA in the decidual tissues was extracted using TRIzol ${ }^{\circledR}$ reagent (Invitrogen, Carlsbad, USA). The extracted RNA was reversely transcribed into cDNA by the TaqMan ${ }^{\circledR}$ MicroRNA Reverse Transcription Kit (4427975; Applied Biosystems, Foster City, USA). The reverse transcription reaction volume was set as $25 \mu \mathrm{L}$. The reaction was performed at $37^{\circ} \mathrm{C}$ for $30 \mathrm{~min}$, and the inactivation reaction was done at $85^{\circ} \mathrm{C}$ for 5 s. Primers designed for miR-24, CDX1, GAPDH, and U6 were synthesized by Beijing Tsingke Biotechnology Co., Ltd., Beijing, China (Table 1). Reverse-transcriptase quantitative PCR was processed using ABI7500 real-time quantitative PCR instrument (Thermo Fisher Scientific, Waltham, USA). The reaction conditions were as follows: pre-denaturation at $95^{\circ} \mathrm{C}$ for $10 \mathrm{~min}$, denaturation at $95^{\circ} \mathrm{C}$ for $10 \mathrm{~s}$, annealing at $60^{\circ} \mathrm{C}$ for $20 \mathrm{~s}$, and lastly extension at $72^{\circ} \mathrm{C}$ for $2 \mathrm{~min}$, 
Table 1. Primer sequences

\begin{tabular}{|c|c|}
\hline Gene & Primer sequence $\left(5^{\prime}-3^{\prime}\right)$ \\
\hline \multirow{2}{*}{ miR-24 } & F: GGGTGGCTCAGTTCAGCAG \\
\hline & R: GTGCAGGGTCCGAGGT \\
\hline \multirow{2}{*}{ U6 } & F: CTCGCTTCGGCAGCACATA \\
\hline & R: AACGATTCACGAATTTGCGT \\
\hline \multirow{2}{*}{ CDX1 } & F: GATGGCCTCAATGGGTACAAG \\
\hline & R: TCGTTGTTGTTGATGTCACAGT \\
\hline \multirow{2}{*}{ GAPDH } & F:TGGCCTTCCGTGTTCCTAC \\
\hline & R: GAGTTGCTGTTGAAGTCGCA \\
\hline
\end{tabular}

F-forward; $\mathrm{R}$ - reverse; CDX1 - caudal type homeobox 1.

with 35 cycles. The PCR system was set as $20 \mu \mathrm{L}$, containing $0.8 \mu \mathrm{L}$ of qPCR forward primer $(10 \mu \mathrm{M}), 0.8 \mu \mathrm{L}$ of qPCR reverse primer $(10 \mu \mathrm{M}), 0.4 \mu \mathrm{L}$ of ROX reference dye II, $10 \mu \mathrm{L}$ of SYBR ${ }^{\circledR}$ Premix Ex Taq ${ }^{\mathrm{TM}}$ II (Thermo Fisher Scientific), $2.0 \mu \mathrm{L}$ of cDNA template, and $6.0 \mu \mathrm{L}$ of sterilized distilled water. The U6 and GAPDH were used as internal controls for the relative expression of miR-24 and CDX1 mRNA, respectively. The relative expression level of each target gene was calculated with $2^{-\Delta \Delta \mathrm{Ct}}$ method, where $\Delta \Delta \mathrm{Ct}=\Delta \mathrm{Ct}_{\text {experimental group }}$ $-\Delta \mathrm{Ct}_{\mathrm{GAPDH}}$, in which $\Delta \mathrm{Ct}=\mathrm{Ct}_{\text {target gene }}-\mathrm{Ct}_{\text {internal control }}$. $\mathrm{Ct}$ referred to the amplification cycles.

\section{Dual-luciferase reporter gene assay}

The binding sites of miR-24 to CDX1 gene within the 3'-UTR were analyzed through the bioinformatics prediction website (https://cm.jefferson.edu/rna22/). The target relationship between miR-24 and CDX1 was verified using dual-luciferase reporter gene assay. The 3' UTR of CDX1 gene and the 3' UTR of mutated CDX1 gene were respectively inserted into the dual-luciferase reporter gene vector pGL3-Basic, and 2 vectors were named as PGL3-CDX1 wt and PGL3-CDX1 mut, respectively. Renilla plasmid and the 2 reporter gene vectors were respectively co-transfected with miR-24 mimic and miR-24 mimic NC into human embryonic kidney (HEK) 293T cells. After 24 h of cell transfection, dual-luciferase activity was detected using the dual-luciferase reporter gene assay. The cells of each group were lysed and then centrifuged at 12,000 rpm for $1 \mathrm{~min}$, and the supernatant was collected. The dual-luciferase reporter assay kit was purchased from Promega (Boston, USA) and luciferase activity was measured according to the instructions of the kit.

\section{Western blotting}

Western blotting was used to detect the expression levels of cleaved caspase-3, Fas, FasL, and VEGF in decidual tissues of the mice. Decidual tissue homogenate was again prepared for western blotting. Protein extraction was performed using RIPA cell lysis reagent (BB-3209; BestBio Technology, Co., Ltd., Shanghai, China). The proteins were separated with SDS-PAGE and transferred to polyvinylidene difluoride (PVDF) membrane at a constant voltage of $80 \mathrm{~V}$. After being sealed by blocking solution for $1 \mathrm{~h}$, the membrane was incubated with anti-rabbit primary antibodies against cleaved caspase-3 (1: 500; ab49822; Abcam, Cambridge, UK), Fas (1: 1,000; ab15285; Abcam), FasL (1: 1,000; ab15285; Abcam), VEGF (1: 1,000; Ab27278; Abcam) and GAPDH (1: 2,500; ab9485; Abcam), and sealed for incubation with shaking overnight at $4^{\circ} \mathrm{C}$. Then, the membrane was incubated with horseradish peroxidase (HRP)-labeled goat anti-rabbit IgG (1: 2,000; ab205718; Abcam) with shaking at $37^{\circ} \mathrm{C}$ for $2 \mathrm{~h}$. The PVDF membrane was color-developed and photographed. The relative expression of a target protein = the gray value of the target band/the gray value of the internal control band.

\section{TUNEL fluorescence assay}

TUNEL fluorescence detection kit (Roche, Basel, Switzerland) was used to detect the cell apoptosis of decidual tissues in all mice. Paraffin blocks of fixed decidual tissues of all mice were made and sliced into serial sections. Then, the sections were mounted onto glass slides and numbered in sequence. Subsequently, the slices with sections were dewaxed and hydrated, and reacted with cell permeabilization reagent for $8 \mathrm{~min}$, followed by washing with phosphate-buffered saline (PBS) twice. The $50 \mu \mathrm{L}$ TUNEL reaction mixture was added to the slides for $1 \mathrm{~h}$ in a wet box at room temperature, followed by 3 washes with PBS. The treated slides were observed under a Nikon eclipse TE2000-U fluorescence microscope (Nikon, Tokyo, Japan). The average number of TUNEL positive cells was observed using Image-Pro Plus v. 6.0 software by randomly selecting 5 visual fields under a light microscope.

\section{Immunofluorescent assay}

The decidual tissue sections of all the mice were made and then mounted onto glass slides. Slices were sealed with primary antibody mouse anti-VEGF (1: 100; ab205; Abcam), incubated at room temperature for $1 \mathrm{~h}$ and sealed by FITC conjugated goat anti-mouse IgG antibody (1: 200; ab150117; Abcam) for $30 \mathrm{~min}$. Then, the nucleus was stained by Invitrogen $^{\mathrm{TM}}$ Molecular Probes ${ }^{\mathrm{TM}}$ DAPI (4,6-diamidino-2-phenylindole, dihydrochloride) for $10 \mathrm{~min}$. After ten-minute staining, the slides were washed 3 times with $1 \times$ PBS for 10 min each time to prevent fluorescence quenching agent from entering the sealed sections. The slides were observed under a fluorescence microscope (XSP-BM22AY; Shanghai Optical Instrument Factory, Shanghai, China).

\section{Statistical analysis}

Data analyses were performed with the SPSS v. 21.0 software package (IBM Corp., Armonk, USA). All measurement data were expressed as mean \pm standard deviation 


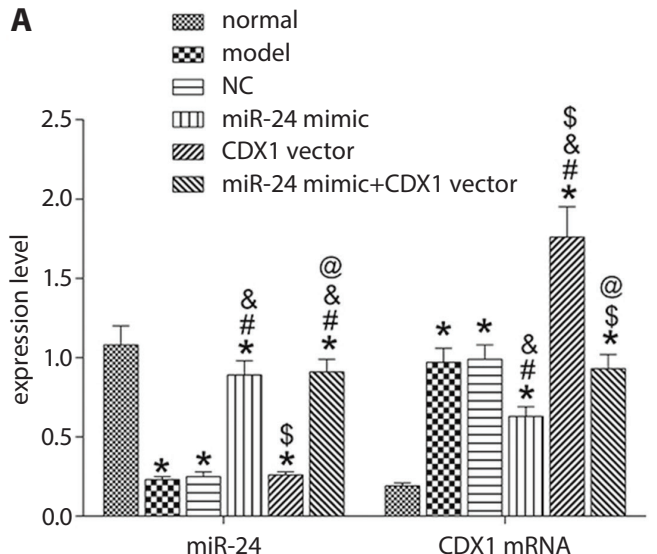

C

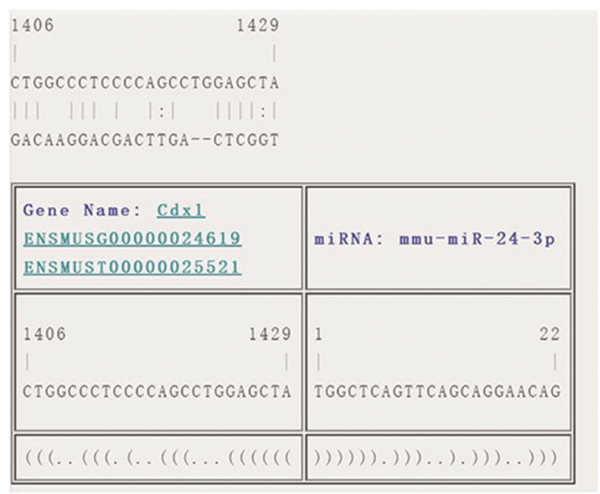

(SD). Pairwise comparisons among groups were conducted with one-way analysis of variance (ANOVA) test combined with Bonferroni post hoc test. A value of $\mathrm{p}<0.05$ was considered statistically significant.

\section{Results}

\section{MiR-24 can negatively regulate CDX1 expression}

The expressions of miR-24 and CDX1 in decidual tissues of the mice detected using qRT-PCR are shown in Fig. 1A. Compared with the normal group, miR-24 expression level significantly decreased but CDX1 significantly increased in other groups (all p < 0.05). Compared with the model group, miR-24 expression level in miR-24 mimic group was significantly increased, with significant decrease in CDX1 expression; miR-24 expression level in the miR-24 mimic+CDX1 vector group was significantly increased $(\mathrm{p}<0.05)$, but with no significant change in CDX1 expression level ( $p>0.05$ ); CDX1 expression level in the CDX1 vector group was significantly increased $(p<0.05)$, but with no significant change in miR-24 expression level ( $\mathrm{p}>0.05)$.

We found a significant negative correlation between miR24 and CDX1 in 120 female mice as shown in Fig. 1B. Since a binding site between miR-24 and CDX1 was predicted
Fig. 1. MiR-24 can negatively regulate CDX1 expression. A. The expressions of miR-24 and CDX1 in decidual tissues of the mice through qRT-PCR; compared with the normal group, ${ }^{*} \mathrm{p}<0.05$; compared with the model group, $" \mathrm{p}<0.05$; compared with the NC group, ${ }^{\&} p<0.05$; compared with the miR-24 mimic group, s $<<0.05$; compared with CDX1 vector group, ${ }^{\oplus} p<0.05 ;$ B. Correlation analysis between miR-24 and CDX1; C. The targeted relationship between miR-24 and CDX1 through dualluciferase reporter gene assay; D. The results of dual-luciferase reporter gene assay. Compared with NC mimic, ${ }^{*} \mathrm{p}<0.05$

CDX1 - caudal type homeobox 1 .

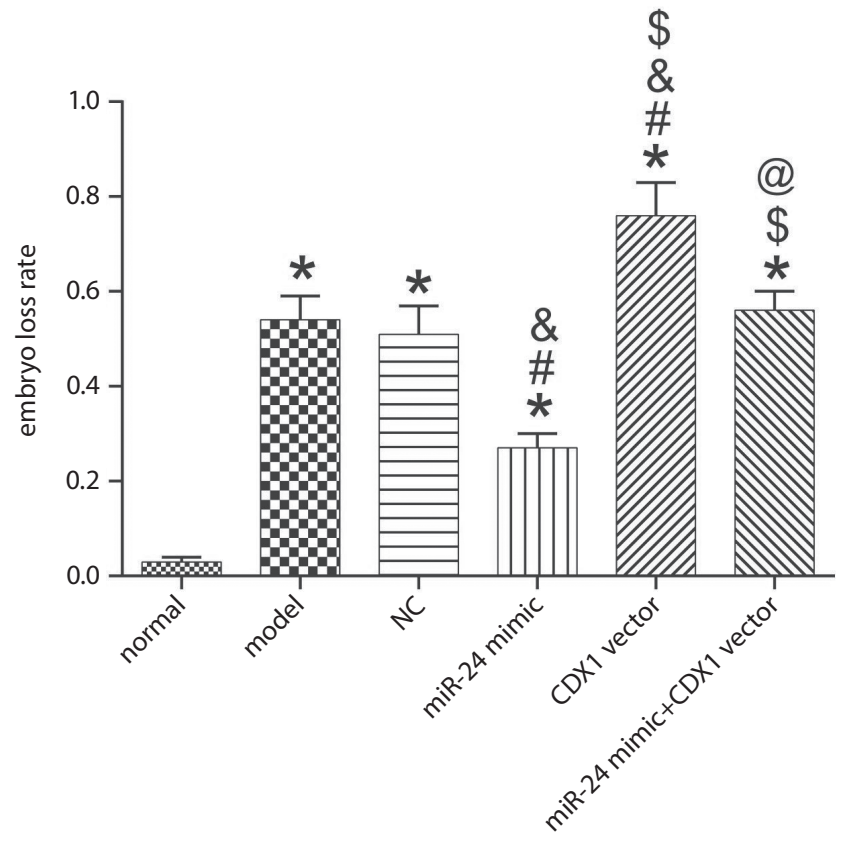

Fig. 2. Comparisons between groups of mice in embryonic loss rate. Compared with the normal group, ${ }^{*} p<0.05$; compared with the model group, ${ }^{*} \mathrm{p}<0.05$; compared with the NC group, ${ }^{*} \mathrm{p}<0.05$; compared with the miR-24 mimic group, $\$ p<0.05$; compared with the CDX1 vector group, ${ }^{\circledR} \mathrm{p}<0.05$

CDX1 - caudal type homeobox 1. 


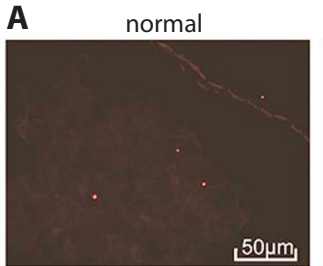

miR-24 mimic
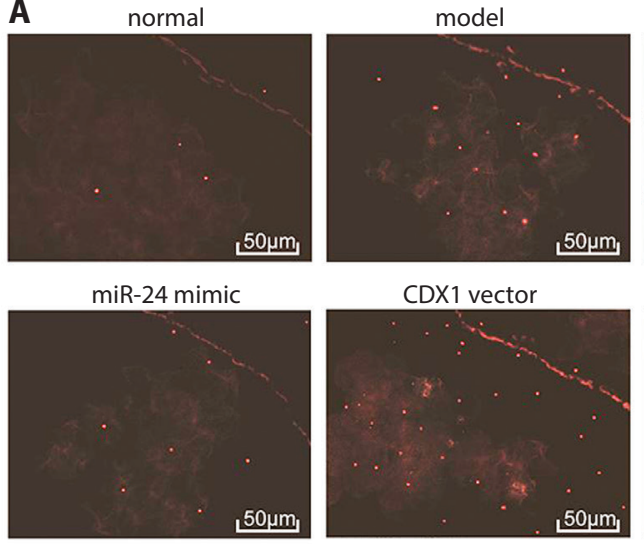

CDX1 vector
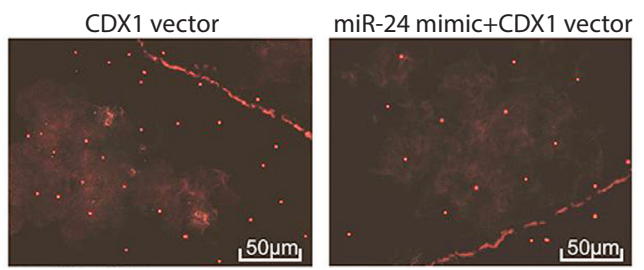

B

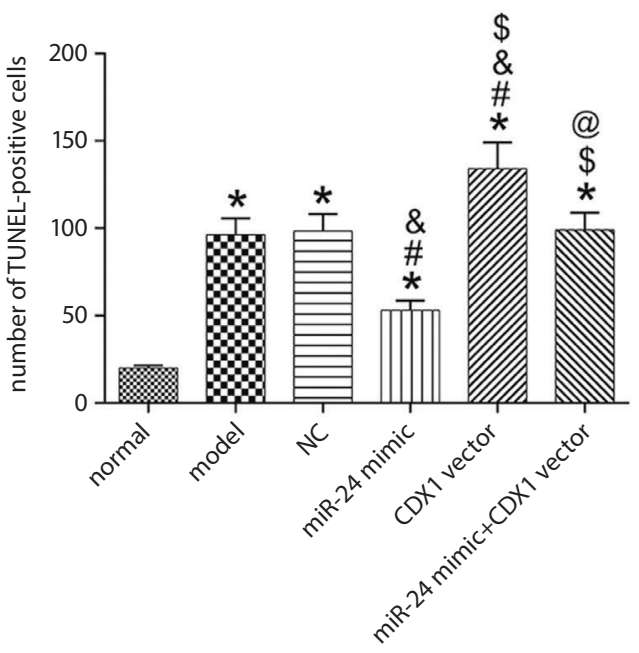

C

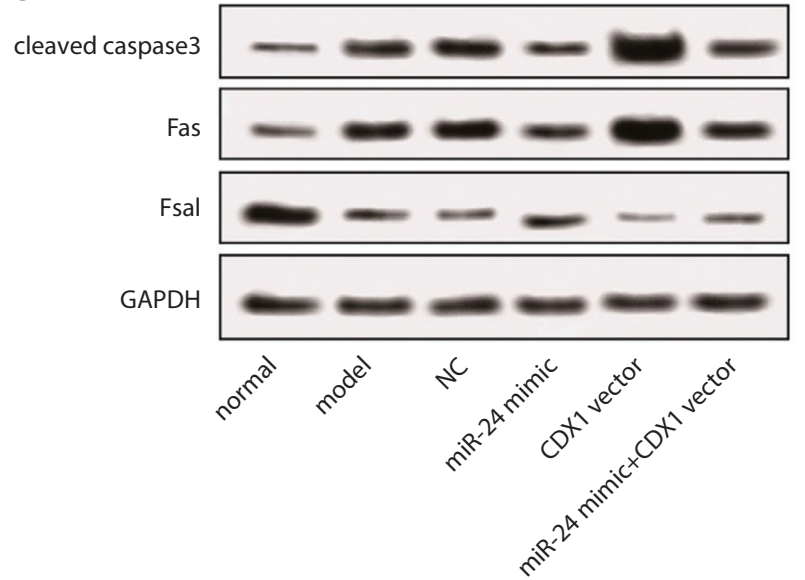

D

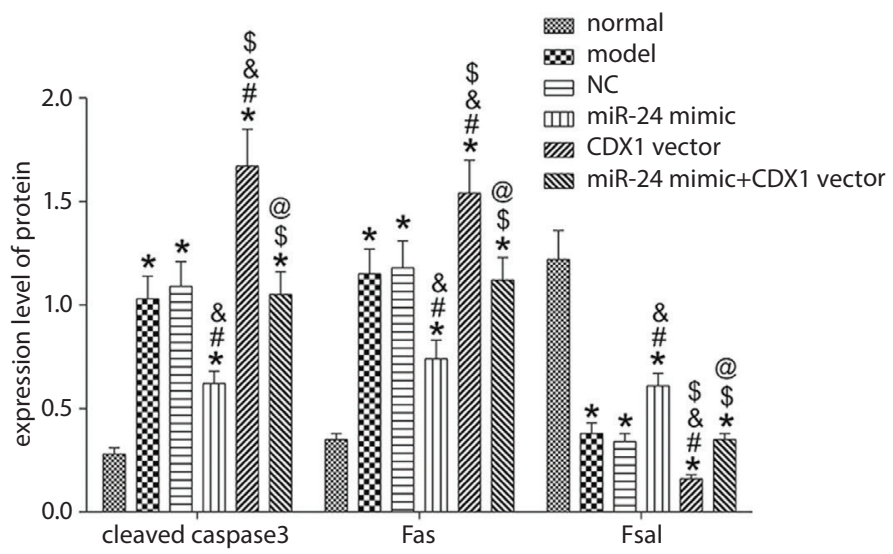

Fig. 3. Analysis of apoptosis in decidual tissues of the mice. The apoptosis (A) and the numbers of apoptotic cells (B) in decidual tissue of the mice through TUNEL fluorescence assay; C. Western blot bands; D. Detection results of apoptosis-related factors. Compared with the normal group, ${ }^{*} \mathrm{p}<0.05 ;$ compared with the model group, ${ }^{\#} p<0.05$; compared with the NC group, ${ }^{\&} p<0.05$; compared with the miR-24 mimic group, $\$ p<0.05$; compared with the CDX1 vector group, ${ }^{\circ} \mathrm{p}<0.05$

CDX1 - caudal type homeobox 1.

by RNA22, we hypothesized that miR-24 may act as an upstream regulatory element regulating CDX1 expression, so we performed gene assay using a dual-luciferase reporter to test binding sites. The results in Fig. 1C and 1D showed that luciferase activity was significantly decreased after co-transformation of wild-type CDX1 reporter plasmid and miR-24 mimic ( $<$ 0.05), indicating that miR-24 can targetedly and negatively regulate CDX1 expression.

\section{Embryonic development of the mice}

The mice were sacrificed at day 14 after pregnancy, and the uteri were then removed for observation for the embryonic development of all mice to obtain the embryo loss rate (Fig. 2). A higher embryo loss rates was observed in other groups when compared to that in the normal group (all $\mathrm{p}<0.05)$. Additionally, when compared with the model group, opposite results occurred in the miR-24 mimic group, while similar results were obtained in the CDX1 vector group (both $\mathrm{p}<0.05$ ).

\section{Cell apoptosis of decidual tissues of the mice}

Cell apoptosis of decidual tissues may be one of the causes contributing to mouse embryo death and RSA. We detected the cell apoptosis of decidual tissues in all mice using TUNEL fluorescence assay, and the results are shown in Fig. 3A and 3B. The normal group has significantly more TUNEL positive cells than other groups. The number of TUNEL positive cells significantly decreased in miR-24 mimic group, but significantly increased in CDX1 vector group when compared to that in the model group, which was significantly elevated in the miR-24 mimic+CDX1 vector group when compared with that in the miR-24 mimic group, while significantly decreased in the miR-24 mimic+CDX1 vector group when compared to that in the CDX1 vector group $(\mathrm{p}<0.05)$. Additionally, we detected the expression levels of apoptosisrelated factors, cleaved caspase-3, Fas and FasL, through western blotting. The results in Fig. $3 \mathrm{C}$ and $3 \mathrm{D}$ show that 
A

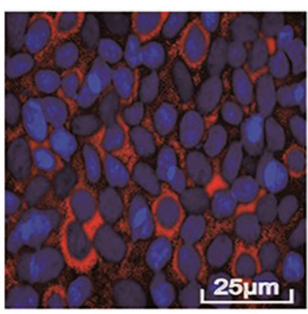

miR-24 mimic
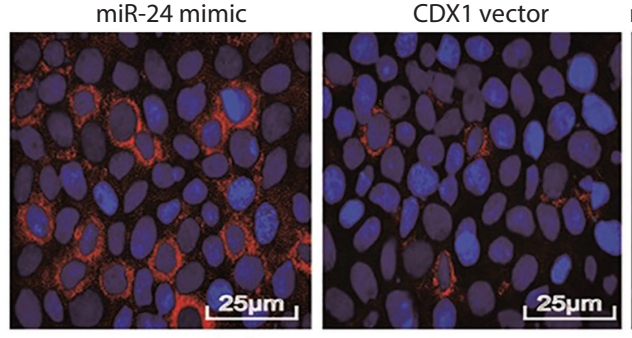

NC

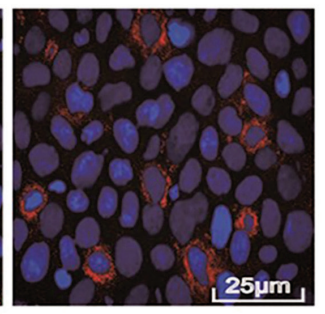

miR-24 mimic+CDX1 vector

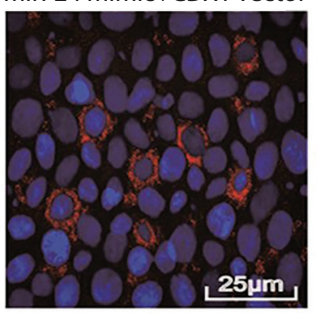

B

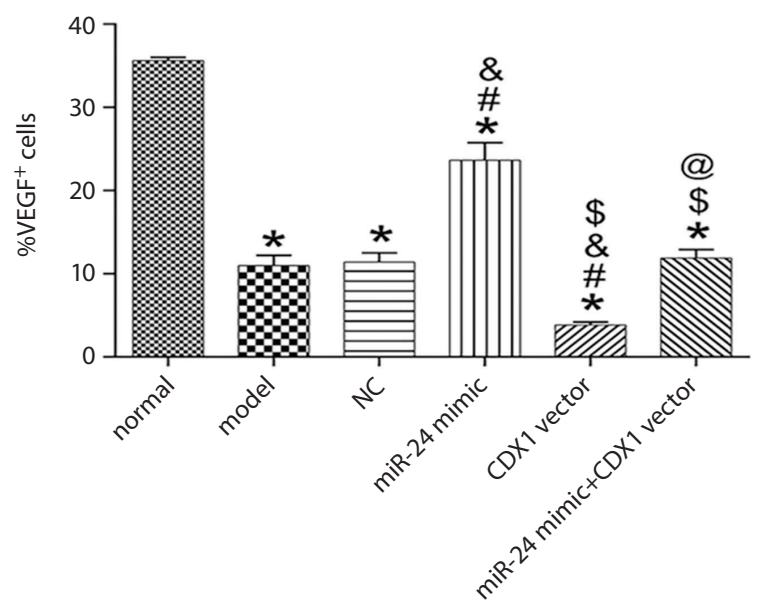

C

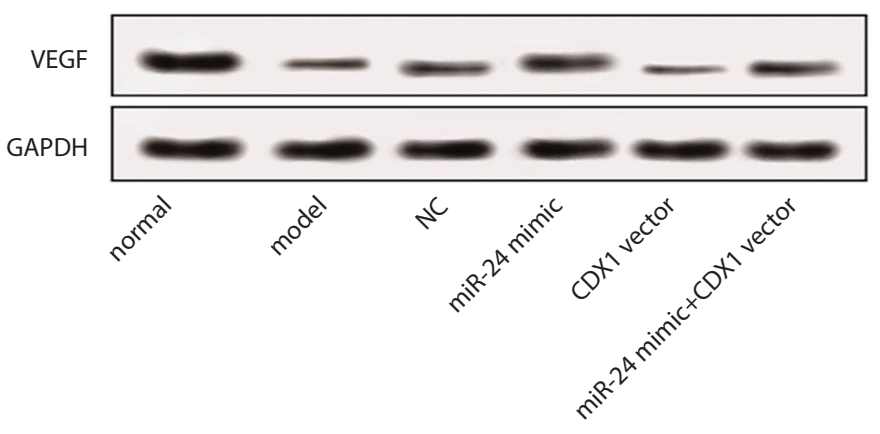

D

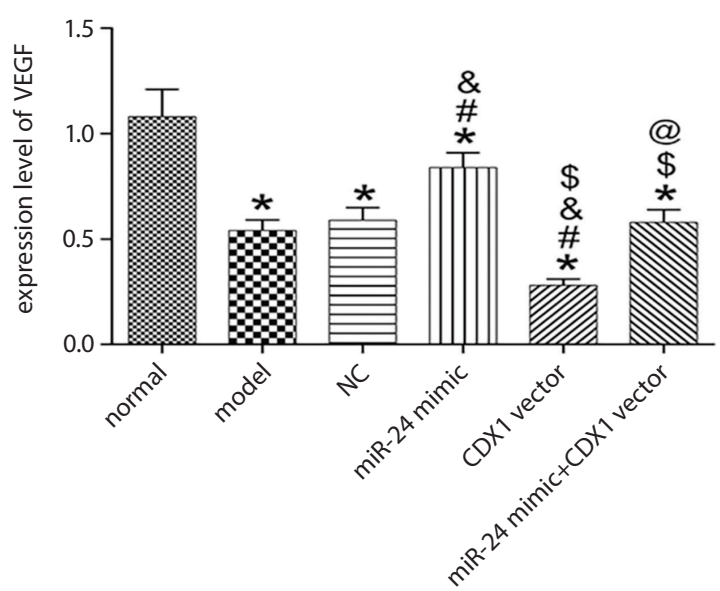

Fig. 4. Immunohistochemical results of rats in all groups. A. Microscopic image of immunohistochemical staining ( $\times 400$ magnification). B. Statistical analysis of the number of VEGF-positive cells in all groups; C. Western blot bands; D. Statistical analysis of VEGF protein expression. Compared with the normal group, ${ }^{*} p<0.05$; compared with the model group, ${ }^{*} p<0.05$; compared with the NC group, ${ }^{\&} p<0.05$; compared with the miR-24 mimic group, $\$ p<0.05$; compared with the CDX1 vector group, ${ }^{\circledR} \mathrm{p}<0.05$

CDX1 - caudal type homeobox 1; GAPDH - glyceraldehyde-3-phosphate dehydrogenase.

overexpression of miR-24 could inhibit the expressions of cleaved caspase- 3 and Fas, and promote the expression of FasL, while CDX1 overexpression showed the opposite changes. These results comprehensively confirmed that miR-24 overexpression can significantly reduce the cell apoptosis of decidual tissue, while overexpression of CDX1 can promote the apoptosis of decidual tissues in mice; moreover, CDX1 overexpression can block the inhibitory effect of miR-24 overexpression on the apoptosis of decidual tissues in mice.

\section{VEGF expression of decidual tissues of the mice}

The expression of VEGF in decidual tissues was detected with immunofluoresce assay, and the results are shown in Fig. 4A and 4B. The normal group has significantly higher fluorescence expression levels of VEGF in decidual tissues than other groups ( $\mathrm{p}<0.05$ ). The VEGF fluorescence expression was significantly higher in miR-24 mimic group, while significantly lower in CDX1 vector group when compared to that in the model group $(\mathrm{p}<0.05)$. Additionally, we detected the protein expression of VEGF using western blotting (Fig. 4C,D), and the results were consistent with expression trend in the immunofluoresce assay.

\section{Discussion}

Recurrent spontaneous abortion presents high incidence among pregnant women, with high difficulty in treatment and cure. The mechanism of RSA under exploration may serve as a crucial guiding role in clinical treatment. ${ }^{17,18}$ In this study, we mainly focused on decidual tissue, which plays a vital role in the occurrence and maintenance of a pregnancy. ${ }^{19}$ 
Initially, we found that CDX1 may be overexpressed in RSA through preliminary experiments. Meanwhile, some literatures showed that CDX1 may have aggravating effect on the condition of RSA. Therefore, we constructed RSA mouse models and detected the expression of CDX1 in normal pregnant mice and RSA mice, and the results were consistent with the results of the bioinformatics prediction. Thus, we performed overexpression on CDX1 in RSA mice. The results showed that the fatality rate of treated mouse embryos increased significantly, suggesting that the development of mouse embryos evidently deteriorated after overexpression of CDX1. Additionally, we detected the apoptosis of decidual tissues and found that the apoptosis rate of decidual tissues in the mice increased significantly after CDX1 overexpression. VEGF plays a highly favorable role in the auxoaction for vascular remodeling of endometrium tissue, thus further facilitating differentiation of trophoblastic cells of mouse embryo and embryo implantation, conclusively promoting mouse embryo development. ${ }^{20-22}$ We found that the expression level of VEGF after overexpression of CDX1 decreased significantly. Based on the above experiments, we speculate that CDX1 overexpression in the RSA mice may not only lead to apoptosis of decidual tissue and instability of embryo development during pregnancy, but also cause inhibition on VEGF expression and embryo implantation, thus hindering the development of mouse embryo and giving rise to further occurrence of RSA.

The bioinformatics prediction website also found a binding site between miR-24 and CDX1. We also detected the expression of miR-24 in normal pregnant mice and RSA mice, and verified the binding relationship between miR-24 and CDX1 using dual-luciferase reporter gene assay. The results show that miR-24 expression was downregulated in RSA mice, and miR-24 could target CDX1 and inhibit its expression. The phenotypic results in RSA mice receiving overexpression on $\mathrm{miR}-24$ were opposite to those receiving overexpression on CDX1. In addition, compared with the RSA mice receiving miR-24 overexpression, the apoptosis ratio of decidual tissue in the RSA mice treated with overexpression on both miR-24 and CDX1 was significantly elevated, with significant reduction on VEGF expression. Based on the above results, we speculate that miR-24 overexpression can reduce apoptosis of decidual tissue and increase VEGF expression by inhibiting CDX1 expression in RSA mice, thus improving mouse embryo development and lowering abortion rate.

However, the causes of RSA are complex, and contributors also include endocrine disorders, body immunity and prethrombotic state apart from the effects of decidual tissue and uterus implantation. ${ }^{23-28}$ However, this study mainly aimed to explore the effects of miR-24 and CDX1 on apoptosis of decidual tissue and VEGF expression, and it is not clear whether miR-24 and CDX1 have regulatory effects on endocrine, immune function and prethrombotic state of pregnant mice.

\section{Conclusions}

We confirmed the expressions of miR-24 and CDX1 in decidual tissues of RSA mice and also the expression regulation relationship between them, which further enriches the mechanism of RSA, potentially providing a new idea for clinical treatment on RSA.

\section{ORCID iDs}

Shuyan Wang (D) https://orcid.org/0000-0003-1629-5176

Shishan Guo (D) https://orcid.org/0000-0001-7119-9641

Xiaoyan Hou (D) https://orcid.org/0000-0002-0645-8018

\section{References}

1. Karim S, Jamal HS, Rouzi A, et al. Genomic answers for recurrent spontaneous abortion in Saudi Arabia: An array comparative genomic hybridization approach. Reprod Biol. 2017;17(2):133-143.

2. Sun Q, Zhang XL. Research on apoptotic signaling pathways of recurrent spontaneous abortion caused by dysfunction of trophoblast infiltration. Eur Rev Med Pharmacol Sci. 2017;21(3 Suppl):12-19.

3. Al-Azawi IH, Khaleel SH, Al-Khafaji GK. Using PCR assay for detection and subtyping of Ureaplasma parvum in women with recurrent abortion. Rev Med Microbiol. 2017;28(1):26-29.

4. Yang HL, Zhou WJ, Gu CJ, et al. Pleiotropic roles of melatonin in endometriosis, recurrent spontaneous abortion, and polycystic ovary syndrome. Am J Reprod Immunol. 2018;80(1):e12839.

5. Ling Y, Huang Y, Chen C, Mao J, Zhang H. Low dose cyclosporin A treatment increases live birth rate of unexplained recurrent abortion: Initial cohort study. Clin Exp Obstet Gynecol. 2017;44(2):230-235.

6. Huang XJ, Wang X, Ma X, et al. EZH2 is essential for development of mouse preimplantation embryos. Reprod Fertil Dev. 2014;26(8): 1166-1175.

7. Dong X, Yang L, Wang H. miR-520 promotes DNA-damage-induced trophoblast cell apoptosis by targeting PARP1 in recurrent spontaneous abortion (RSA). Gynecol Endocrinol. 2017;33(4):274-278.

8. Zhao L, Li J, Huang S. Patients with unexplained recurrent spontaneous abortion show decreased levels of microrna-146a-5p in the deciduae. Ann Clin Lab Sci. 2018;48(2):177-182.

9. Chen $\mathrm{H}$, Yang $\mathrm{Q}$, Chen $\mathrm{K}$, et al. Integrated microRNA and transcriptome profiling reveals a miRNA-mediated regulatory network of embryo abortion under calcium deficiency in peanut (Arachis hypogaea L.). BMC Genomics. 2019;20(1):392.

10. Lu XY, Chen D, Gu XY, et al. Predicting value of ALCAM as a target gene of microRNA-483-5p in patients with early recurrence in hepatocellular carcinoma. Front Pharmacol. 2017;8:973.

11. Zhu Y, Lu H, Huo Z, et al. MicroRNA-16 inhibits feto-maternal angiogenesis and causes recurrent spontaneous abortion by targeting vascular endothelial growth factor. Sci Rep. 2016;6:35536.

12. Li D, Li J. Association of miR-34a-3p/5p, miR-141-3p/5p, and miR-24 in decidual natural killer cells with unexplained recurrent spontaneous abortion. Med Sci Monit. 2016;22:922-929.

13. Wang X, Li B, Wang J, et al. Evidence that miR-133a causes recurrent spontaneous abortion by reducing HLA-G expression. Reprod Biomed Online. 2012;25(4):415-424.

14. Yuan Y, Kluiver J, Koerts J, et al. miR-24-3p is overexpressed in Hodgkin lymphoma and protects Hodgkin and Reed-Sternberg cells from apoptosis. Am J Pathol. 2017;187(6):1343-1355.

15. Sadighi-Moghaddam B, Salek Farrokhi A, Namdar Ahmadabad H, Barati M, Moazzeni SM. Mesenchymal stem cell therapy prevents abortion in CBA/J x DBA/2 mating. Reprod Sci. 2018;25(8):1261-1269.

16. Amsalem H, Kwan M, Hazan A, et al. Identification of a novel neutrophil population: Proangiogenic granulocytes in second-trimester human decidua. J Immunol. 2014;193(6):3070-3079.

17. Lv S, Wang $\mathrm{N}, \mathrm{Lv} \mathrm{H}$, et al. The attenuation of trophoblast invasion caused by the downregulation of EZH2 is involved in the pathogenesis of human recurrent miscarriage. Mol Ther Nucleic Acids. 2019;14: 377-387.

18. Park DW, Lee HJ, Park CW, Hong SR, Kwak-Kim J, Yang KM. Peripheral blood NK cells reflect changes in decidual NK cells in women with recurrent miscarriages. Am J Reprod Immunol. 2010;63(2):173-180. 
19. Ahn JH, Park HR, Park CW, Park DW, Kwak-Kim J. Expression of TWIST in the first-trimester trophoblast and decidual tissue of women with recurrent pregnancy losses. Am J Reprod Immunol. 2017;78(2). doi:10. 1111/aji.12670

20. Su MT, Tsai PY, Tsai HL, Chen YC, Kuo PL. miR-346 and miR-582-3pregulated EG-VEGF expression and trophoblast invasion via matrix metalloproteinases 2 and 9. Biofactors. 2017;43(2):210-219.

21. Zhi Z, Yang W, Liu L, Jiang X, Pang L. Early missed abortion is associated with villous angiogenesis via the HIF-1alpha/VEGF signaling pathway. Arch Gynecol Obstet. 2018;298(3):537-543.

22. Xia S, Zhen $\mathrm{Y}, \mathrm{Ma} \mathrm{H}$, Wang A. Abnormal expression of microRNA-575 leads to missed abortion through regulating apoptosis and angiogenesis. Exp Ther Med. 2017;14(5):3993-4000.

23. Starchenko, II, Vitko YN, Prylutskyi OK, Bilokon SO, Vynnyk NI. Morphological and immunohistochemical characteristics of human trigeminal ganglion neurons in the prenatal period of development. Wiad Lek. 2017;70(3 Pt 2):561-565.
24. Yang J, Wang Y, Wang XY, Zhao YY, Wang J, Zhao YY. Adverse pregnancy outcomes of patients with history of first-trimester recurrent spontaneous abortion. Biomed Res Int. 2017;2017:4359424.

25. Feli A, Jazayeri S, Bitaraf MA, Solaymani Dodaran M, Parastouei K, Hosseinzadeh-Attar MJ. Combination therapy with low copper diet, penicillamine and gamma knife radiosurgery reduces VEGF and IL-8 In patients with recurrent glioblastoma. Asian Pac J Cancer Prev. 2017; 18(7):1999-2003.

26. Zhu L, Chen H, Liu M, et al. Treg/Th17 cell imbalance and IL-6 profile in patients with unexplained recurrent spontaneous abortion. Reprod Sci. 2017;24(6):882-890.

27. Stavrou S, Gratz M, Tremmel E, et al. TAAR1 induces a disturbed GSK3beta phosphorylation in recurrent miscarriages through the ODC. Endocr Connect. 2018;7(2):372-384.

28. Gao Y, Hong X, Wang Z, Zhu Y. Endometrial receptivity and conception outcome among women with light menstrual bleeding of unidentified etiology. Int J Gynaecol Obstet. 2018;140(1):37-41. 